\title{
Genetic variation of TLR4 influences immunoendocrine stress response: an observational study in cardiac surgical patients
}

\author{
Alexander Koch ${ }^{1 *}$, Lutz Hamann², Matthias Schott ${ }^{3}$, Olaf Boehm ${ }^{4}$, Dirk Grotemeyer ${ }^{5}$, Muhammed Kurt ${ }^{6}$, \\ Carsten Schwenke ${ }^{7}$, Ralf R Schumann ${ }^{2}$, Stefan R Bornstein ${ }^{8}$ and Kai Zacharowski ${ }^{1}$
}

\begin{abstract}
Introduction: Systemic inflammation (for example, following surgery) involves Toll-like receptor (TLR) signaling and leads to an endocrine stress response. This study aims to investigate a possible influence of TLR2 and TLR4 single nucleotide polymorphisms (SNPs) on perioperative adrenocorticotropic hormone (ACTH) and cortisol regulation in serum of cardiac surgical patients. To investigate the link to systemic inflammation in this context, we additionally measured 10 different cytokines in the serum.
\end{abstract}

Methods: A total of 338 patients admitted for elective cardiac surgery were included in this prospective observational clinical cohort study. Genomic DNA of patients was screened for TLR2 and TLR4 SNPs. Serum concentrations of $A C T H$, cortisol, interferon (IFN)- $\gamma$, interleukin (IL)-1 $\beta, I L-2, I L-4, I L-5, I L-6, I L-8, I L-10$, tumor necrosis factor (TNF)- $\alpha$ and granulocyte macrophage-colony stimulating factor (GM-CSF) were determined before surgery, immediately post surgery and on the first postoperative day.

Results: Thirteen patients were identified as TLR2 SNP carriers, 51 as TLR4 SNP carriers and 274 patients as noncarriers. Basal levels of ACTH, cortisol and cytokines did not differ among groups. In all three groups a significant, transient perioperative rise of cortisol could be observed. However, only in the non-carrier group this was accompanied by a significant ACTH rise. TLR4 SNP carriers had significant lower ACTH levels compared to noncarriers (mean (95\% confidence intervals)) non-carriers: 201.9 (187.7 to 216.1) pg/ml; TLR4 SNP carriers: 149.9 (118.4 to 181.5$) \mathrm{pg} / \mathrm{ml}$; TLR2 SNP carriers: 176.4 ((110.5 to 242.3$) \mathrm{pg} / \mathrm{ml})$. Compared to non-carriers, TLR4 SNP carriers showed significant lower serum IL-8, IL-10 and GM-CSF peaks (mean (95\% confidence intervals)): IL-8: non-carriers: 42.6 (36.7 to 48.5) pg/ml, TLR4 SNP carriers: 23.7 (10.7 to 36.8) pg/ml; IL-10: non-carriers: 83.8 (70.3 to 97.4) pg/ml, TLR4 SNP carriers: 54.2 (24.1 to 84.2) pg/ml; GM-CSF: non-carriers: 33.0 (27.8 to 38.3) pg/ml, TLR4 SNP carriers: 20.2 (8.6 to 31.8$) \mathrm{pg} / \mathrm{ml}$ ). No significant changes over time or between the groups were found for the other cytokines.

Conclusions: Regulation of the immunoendocrine stress response during systemic inflammation is influenced by the presence of a TLR4 SNP. Cardiac surgical patients carrying this genotype showed decreased serum concentrations of ACTH, IL-8, IL-10 and GM-CSF. This finding might have impact on interpreting previous and designing future trials on diagnosing and modulating immunoendocrine dysregulation (for example, adrenal insufficiency) during systemic inflammation and sepsis.

\footnotetext{
* Correspondence: a.koch@med.uni-frankfurt.de

'Clinic of Anaesthesiology, Intensive Care Medicine and Pain Therapy, J.W.Goethe-University Hospital, Theodor-Stern-Kai 7, Frankfurt am Main 60590, Germany

Full list of author information is available at the end of the article
} 


\section{Introduction}

Toll-like receptors (TLRs) are known to play a crucial role in the innate immune response in mammals. TLRs are involved in the recognition of pathogenic molecules like lipopolysaccharide (LPS), lipoteichoic acid (LTA), bacterial DNA and others [1]. Furthermore, there is good evidence for the involvement of TLRs in the crosstalk of immune system and the hypothalamic-pituitaryadrenal (HPA) axis [2-5]. In TLR2 deficient mice, adrenal glands are significantly larger compared to wild-type mice. However, the corticosterone plasma levels are significantly lower in the deficient mice. Inducing a systemic inflammation with bacterial wall components in TLR2 deficient mice leads to an impaired release of both corticosterone and pro-inflammatory cytokines compared to wild-type animals [6]. A similar difference of physiology and pathophysiology of the HPA axis exists between wild-type and TLR4 deficient mice. Under physiological conditions the cortex of the adrenal glands is significantly enlarged and plasma concentrations of corticosterone and the pro-inflammatory cytokines tumor necrosis factor (TNF)- $\alpha$, interleukin (IL)- $1 \beta$ and IL-12 are significantly higher when compared to wild-type animals. Systemic inflammation induces an increase of corticosterone plasma concentration in wildtype, but a decrease in TLR4 deficient mice [7].

In humans, single nucleotide polymorphisms (SNPs) are described. For TLR2 the most investigated SNP is Arg753Gln which is located in the coding region with a prevalence of approximately 3 to $9.4 \%$ in the Caucasian population [8-13]. Children carrying the SNP of Arg753Gln are more susceptible to febrile infections compared to non-carriers [13]. Furthermore, the Arg753Gln polymorphism has been reported to increase the risk of gram-positive and candida sepsis in critical ill patients $[8,10]$, and to increase restenosis rate in patients who underwent percutaneous transluminal coronary angioplasty [14].

The two most investigated SNPs of TLR4 are Asp299Gly and Thr399Ile. Six to 14\% of the European population are double heterozygote carriers, whereas less than 0.3\% carry either the Asp299Gly or the Thr399Ile SNP alone [15]. Compared to non-carriers, Asp299Gly/ Thr399Ile carriers demonstrated a blunted decrease of forced expiratory volume in one second in response to LPS inhalation [16,17], and significant lower plasma levels of the inflammatory markers IL-6, IL-1 $\beta$ and C-reactive protein (CRP) in response to LPS injection [18].

Cardiac surgery leads to the activation of both the immune system and the HPA axis. In particular the application of extracorporal circulation, that is, cardiopulmonary bypass $(\mathrm{CPB})$ with distinct contact between blood and artificial surfaces induces complement system, leucocyte activation and the release of cytokines, nitric oxide and oxygen-free radicals $[19,20]$. The latter pathophysiological changes lead to a systemic inflammatory response and are associated with the release of adrenocorticotropic hormone (ACTH), cortisol [21-23] and various cytokines [24].

In this prospective observational clinical cohort study we aimed to asses the impact of TLR2 and TLR4 polymorphisms on HPA axis regulation and cytokine release related to systemic inflammation during/following cardiac surgery. Primary endpoint was the influence of TLR2 and TLR4 SNP on ACTH and cortisol regulation. Secondary endpoint was the influence of TLR2 and TLR4 SNP on systemic cytokine release.

\section{Materials and methods Patients}

This prospective single center observational clinical cohort study was approved by the local ethical review committee (University Hospital Duesseldorf) and carried out in compliance with the principles established in the Helsinki Declaration. Written consent was obtained from 383 patients undergoing elective cardiac surgery (coronary artery bypass graft (CABG) and/or valve surgery (VS) including replacement and reconstruction). Inclusion criteria: age 18 or older, elective cardiac surgery, on $\mathrm{CPB}$. Exclusion criteria: cardiac surgery performed without $\mathrm{CPB}$, history of diseases affecting the HPA axis, systemic or local treatment with glucocorticoids within 30 days before surgery.

\section{Clinical management}

Following standard oral benzodiazepine premedication the night before surgery and one to two hours preoperative on the day of operation, standard monitoring, peripheral venous and arterial access were established prior to induction. Anesthesia was induced with fentanyl (3 to $4 \mu \mathrm{g} / \mathrm{kg}$ ) and thiopenthal (1 to $2 \mathrm{mg} / \mathrm{kg}$ ). Following muscle relaxation with pancuronium bromide $(100 \mu \mathrm{g} / \mathrm{kg})$, the patient was intubated, ventilated and general anesthesia was maintained using fentanyl and sevoflurane $(0.8$ to $1.5 \mathrm{vol} \%$ end-tidal). Central venous access was established, a rectal temperature probe and a urine catheter were inserted. Prior to CPB the patient was fully heparinized with $300 \mathrm{IU} / \mathrm{kg}$ heparin i.v. achieving an activated clotting time (ACT) of longer than $400 \mathrm{sec}-$ onds. Every patient underwent standard nonpulsatile, hypothermic $\left(28^{\circ} \mathrm{C}\right.$ to $\left.32^{\circ} \mathrm{C}\right) \mathrm{CPB}$ (roller pump: Stöckert, Munich, Germany; membrane oxygenator: Cobe, Arvada, CO, USA). Flow rate initially started at $2.4 \mathrm{~L} /$ minute $/ \mathrm{m}^{2}$ and was further adjusted to maintain a mean arterial blood pressure (MAP) of $60 \mathrm{mmHg}$. Heparin was administered intermittently to maintain ACT 
between 400 and 500 seconds. Bretschneider solution was used for cardioplegia. At the end of surgery heparin was antagonized with protamine $(3 \mathrm{mg} / \mathrm{kg})$ and after rewarming patients' temperature to a minimum of $34^{\circ} \mathrm{C}$, $\mathrm{CPB}$ was weaned off slowly with fluids and/or inotropic agents infused according to central venous pressure or MAP respectively. Patients, intubated, ventilated and sedated were then transferred to the ICU.

\section{Sampling}

Beside routine pre- and postoperative blood tests three consecutive blood samples were obtained from each patient (supine position). Sample A (whole blood and serum): Preoperative, between 07:00 and 09:00; Sample $B$ (serum): Postoperative, on arrival to the intensive care unit (ICU); Sample C (serum): Postoperative Day 1, between 07:00 and 09:00. Whole blood samples were stored at $-80^{\circ} \mathrm{C}$, serum samples were centrifuged and stored at $-20^{\circ} \mathrm{C}$ until laboratory analysis.

\section{DNA preparation and genotyping}

DNA was extracted from whole blood by commercial kits (QIAmp, Qiagen, Hilden, Germany). Genotyping for TLR2 SNP Arg753Gln (rs5743708) and TLR4 SNPs Asp299Gly (rs4986790) and Thr399Ile (rs4986791) was done by melting curve analysis employing FRET probes and the LightcyclerTM (Roche Diagnostics, Mannheim, Germany) as described previously [25]. In brief, 10 to 50 ng genomic DNA was amplified using the following primers: forward: AGTGAGC-GGGATGCCTACT and reverse: GACTTTATCGCAGCTCTCAGATTTAC for TLR2; forward: ATTTAAAGAAATTAGGCTTCATAAGCT and reverse: CCAAGAAGTTTG-AACTCATGGTAA for TLR4. Hybridisation FRET probes CAAGCTGCAGAAGATAA-TGAACACCAAG-FL and LC Red640-CCTACCTGGAGTGGCCCATGGACG for R753Q gave rise to melting peaks at $60.9^{\circ} \mathrm{C}$ for the wildtype allele and $65.4^{\circ} \mathrm{C}$ for the mutated allele. Hybridisation FRET probes CTACTACCTCGATGATATTATTGACTTATT-FL and LC Red640-AATTGTTTGACAAA TGTTTCTTCATTTTCC for Asp299Gly and LC Red705-ATTTTGGGACAACCAGCCTAAAGTAT and CTTGAGTTTCAAAGGTTG-CTGTTCTCAAAGT-FL for Thr399Ile gave rise to melting peaks at $62^{\circ} \mathrm{C}$ and $57.4^{\circ} \mathrm{C}$ or $67^{\circ} \mathrm{C}$ and $60.6^{\circ} \mathrm{C}$ for wild-type and mutated alleles, respectively.

\section{Measurements of ACTH and cortisol}

$\mathrm{ACTH}$ and cortisol serum concentrations were measured by radioimmunoassays (Diagnostic System Laboratories Deutschland DSL, Sinsheim, Germany) as recently described [26]. Concentrations are given as $\mathrm{pg} / \mathrm{ml}$ for ACTH and $\mu \mathrm{g} / \mathrm{dl}$ for cortisol.

\section{Measurements of cytokines}

Serum levels of interferon (IFN) $-\gamma$, IL-1 $1 \beta$, IL-2, IL-4, IL5, IL-6, IL-8, IL-10, TNF- $\alpha$ and granulocyte macrophage-colony stimulating factor (GM-CSF) (Human Cytokine 10-Plex for Luminex ${ }^{\mathrm{TM}}$ laser, BioSource Europe, S.A. Nivelles, Belgium) were determined using the microsphere array technique (Luminex 100 system, Luminex Corp. Austin, TX, USA). Assays were performed according to the manufacturer's protocols [27]. This 10-Plex was chosen because it covers the most important/investigated cytokines in human serum in the context of acute systemic inflammation. Concentrations are given as $\mathrm{pg} / \mathrm{ml}$. Detection limits (in $\mathrm{pg} / \mathrm{ml}$ ): IFN- $\gamma: 5$, IL-1 1 : 15, IL-2: 6, IL-4: 5, IL-5: 3, IL-6: 3, IL-8: 3, IL-10: 5, TNF- $\alpha$ : 10, GM-CSF: 15.

\section{Statistical analysis}

Continuous values are displayed as means and 95\% confidence intervals or medians with interquartile range. Continuous baseline data were tested for differences between the groups TLR2 SNP, TLR4 SNP and non-carriers with two-sided Kruskal-Wallis-tests. Categorical values are displayed as frequencies and percentages. Categorical baseline data were tested for differences between groups by two-sided Fisher's exact tests. The time courses of cortisol, ACTH and cytokines were analysed by means of absolute changes from baseline for time points $\mathrm{A}, \mathrm{B}$, and $\mathrm{C}$ in a linear mixed model. The multiple visits per patient were taken into account. Independence was used as working correlation matrix. Pair wise contrasts were calculated to compare pairs of groups with regard to differences in change from baseline. The factors gender, height, weight, type of surgery, duration of surgery, and outcome of 28-day follow-up were included into the model. Backward selection was used to identify significant factors at a level of 0.05 . Also visit and the interaction group visit were included to test for differences in the course of the values over time. Two-sided $P$-values below 0.05 were regarded as statistically significant. Calculations were performed using SAS 9.2 (SAS Institute Inc., Cary, NC, USA).

\section{Results}

\section{Patient selection, demographic data and baseline} characteristics

All patients fulfilling inclusion criteria who granted informed consent were consecutively enrolled over a period of eight months. There were no changes in anesthetic, surgical, or perfusion techniques during this period. A total of 383 patients were included. Patients were excluded who required reoperation within the period of observation $(n=12)$, were unexpectedly operated without CPB $(n=7)$ or received glucocorticoid therapy 
during or after surgery $(n=6)$. In 10 of the remaining patients genotyping failed for technical reasons. Two more patients identified as SNP carrier for both, TRL2 and TLR4 were excluded. For the remaining 346 patients, frequency distribution analyzes of cortisol- and $\mathrm{ACTH}$ - concentrations in the baseline samples (A) followed. To reduce the undue influence of subjects demonstrating undetected HPA axis pathologies, preoperative systemic inflammation or measurement related discrepancies, outliers were defined as values above 99.5\% tolerance intervals (TI) and subjects demonstrating these outliers were excluded from analyzes. A total of 338 patients, all European Caucasians were included; 13 patients were identified as TLR2, 51 as TLR4 SNP carriers, 274 patients were identified as non-carriers. All TLR2 SNP carriers were heterozygous for Arg753Gln, none homozygous. All TLR4 SNP carriers were heterozygous for both, Asp299Gly and Thr399Ile. None was heterozygous for Asp299Gly or Thr399Ile only. None was homozygous for Asp299Gly or Thr399Ile, none of the patients was identified to be homozygous for both alleles. Each SNP was in Hardy-Weinberg equilibrium (TLR2: $P=0.72$; TLR4: $P=0.13$ ). Demographic data, baseline characteristics and 28-day outcome did not differ between non-carriers, TLR2 SNP and TLR4 SNP carriers with the exception of beta-blocker intake (Table 1). The difference in frequency of beta-blocker intake was further analyzed and found to be absent when comparing non-carriers with TLR4 SNP carriers $(P=0.1257)$.

\section{ACTH and cortisol}

Basal ACTH and cortisol serum levels did not differ between the three genotypes (Figure 1a, b). In all three genotypes cortisol levels significantly raised postoperatively at sample times B and C. However, only in the non-carrier group this was accompanied by a significant $\mathrm{ACTH}$ rise. At sample time $\mathrm{C}$ there was a significant decrease of the ACTH levels compared to sample points $\mathrm{A}$ and $\mathrm{B}$ in the non-carrier group. Neither in the TLR4 SNP nor in the TLR2 SNP carrier group there was a significant difference in changes of ACTH serum concentrations. At sample time B the absolute changes of ACTH levels were significantly different between noncarriers and TLR4 SNP carriers.

\section{Cytokines}

Basal cytokine levels did not differ between the three genotypes (Figure 2a-c, Table 2). Levels of IFN- $\gamma$ in the majority of the measurements were below the detection limit and therefore not analyzed. No significant changes over time or between the groups were found for the cytokines IL-1 $\beta$, IL-2, IL-4, IL-5 and TNF- $\alpha$ (Table 2). IL-6 levels significantly rose on sample time B for all genotype groups and on sample time $C$ for non-carriers

Table 1 Demographic data and baseline characteristics of study population.

\begin{tabular}{|c|c|c|c|c|}
\hline & Non-carrier & TLR2 SNP & TLR4 SNP & $P$-value \\
\hline Number, $n$ & 274 & 13 & 51 & \\
\hline Gender (M/F) & $200 / 74$ & $8 / 5$ & $38 / 13$ & 0.6236 \\
\hline Age, yr (median (IQR)) & $69(62$ to 75$)$ & 74 (66 to 77$)$ & 71 (61 to 77$)$ & 0.1944 \\
\hline Weight, kg (median (IQR)) & 80 (70 to 90$)$ & 80 (70 to 93$)$ & 80 (70 to 90$)$ & 0.7685 \\
\hline Height, m (median (IQR)) & $1.72(1.65$ to 1.76$)$ & 1.68 (1.65 to 1.72$)$ & 1.73 (1.66 to 1.78$)$ & 0.2200 \\
\hline Time of surgery, h & 4.0 (3.4 to 4.7$)$ & 3.8 (3.3 to 4.1$)$ & 3.8 (3.3 to 4.4$)$ & 0.2101 \\
\hline Diabetes mellitus, $n(\%)$ & $96(35)$ & $5(38)$ & $12(24)$ & 0.2375 \\
\hline \multicolumn{5}{|l|}{ Admission medication } \\
\hline Beta-blocker, n (\%) & $215(78)$ & $13(100)$ & $35(69)$ & 0.0362 \\
\hline ACE inhibitor, $n(\%)$ & $137(50)$ & $10(77)$ & $30(59)$ & 0.1048 \\
\hline Calcium channel-blocker, $n$ (\%) & $39(14)$ & $4(31)$ & $4(8)$ & 0.0862 \\
\hline Diuretics, $n(\%)$ & $138(50)$ & $5(38)$ & $25(49)$ & 0.7455 \\
\hline Nitrates, n (\%) & $68(25)$ & $3(23)$ & $11(22)$ & 0.9285 \\
\hline \multicolumn{5}{|l|}{ Type of surgery } \\
\hline CABG, $n(\%)$ & $183(67)$ & $9(69)$ & $36(71)$ & \\
\hline VS, $n(\%)$ & $33(12)$ & $3(23)$ & $4(8)$ & 0.7542 \\
\hline$C A B G+V S, n(\%)$ & $43(16)$ & $1(8)$ & $7(14)$ & \\
\hline Other, $n(\%)$ & $15(6)$ & $0(0)$ & $4(8)$ & \\
\hline \multicolumn{5}{|l|}{ 28-day outcome } \\
\hline Survivor, $n$ (\%) & $247(93)$ & $9(75)$ & $41(89)$ & 0.0753 \\
\hline Nonsurvivor, n (\%) & $19(7)$ & $3(25)$ & $5(11)$ & \\
\hline
\end{tabular}

CABG, coronary artery bypass graft; IQR, interquartile range; TLR2 SNP, toll-like receptor2 single-nucleotide polymorphism carrier; TLR4 SNP, toll-like receptor4 single-nucleotide polymorphism carrier; VS, valve surgery. 


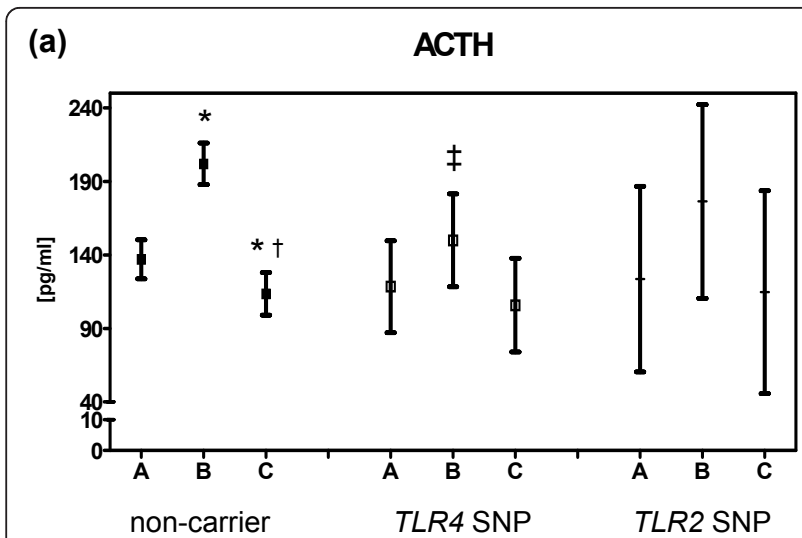

(b)

Cortisol

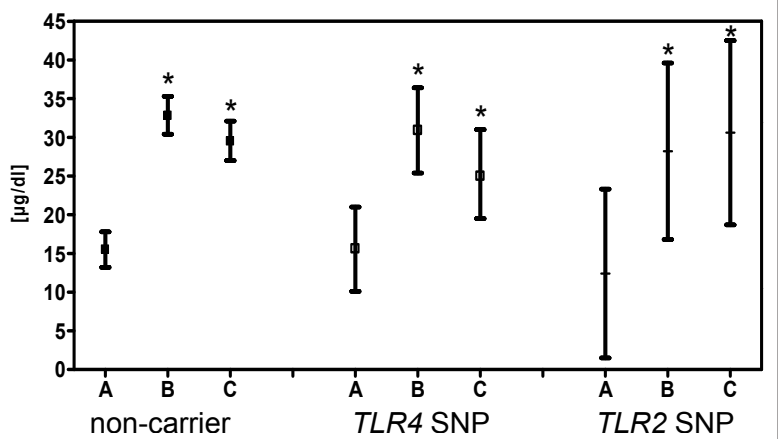

Figure 1 TLR4/TLR2 polymorphisms and time course of perioperative serum concentrations of adrenocorticotropic hormone (ACTH) (a) and cortisol (b). Sampling times: A:

preoperative, B: postoperative at day of surgery, C: postoperative Day 1. TLR2 SNP, toll-like receptor2 single-nucleotide polymorphism carrier; TLR4 SNP, toll-like receptor4 single-nucleotide polymorphism carrier. Number of patients in each group: non-carrier $=274$, TLR4 SNP $=51$, TLR2 SNP $=13$. Values are shown as mean and $95 \%$ confidence intervals. ${ }^{*} P<0.05$ compared to $A_{;}+P<0.05$ compared to $B ; \neq P<0.05$ compared to non-carrier.

and TLR4 SNP carriers. There was a significant decline in the non-carrier group from sample time B to C. No significant differences were found between the genotype groups (Table 2). IL-8 levels were significantly elevated on sample times $B$ and $C$, declining significantly from $B$ to $\mathrm{C}$ in the non-carrier group. In the TLR4 SNP carrier group no significant rise, but even significant lower IL-8 concentrations compared to non-carriers, could be observed. However, there was a transient, significant peak of IL-8 levels in the TLR2 SNP group, represented by a significant rise from $A$ to $B$ and a significant drop from $B$ to $C$ (Figure 2a). IL-10 levels peaked at sample time $B$, that is, significantly increased from A to B and subsequently significantly dropped from $B$ to $C$ in the non-carrier and TLR4 SNP group. IL-10 peak concentrations were significantly lower in TLR4 SNP carriers compared to non-carriers (Figure 2b). GM-CSF levels
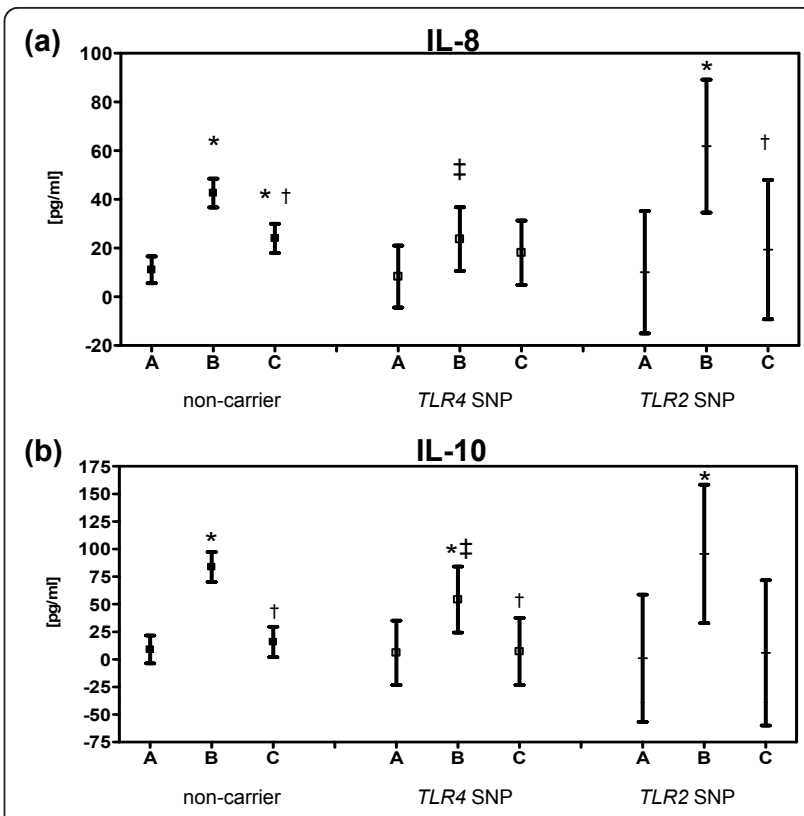

(c)

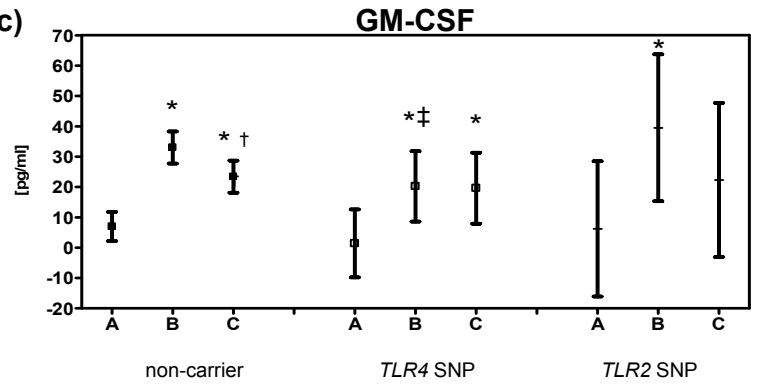

Figure 2 TLR4/TLR2 polymorphisms and time course of perioperative serum concentrations of IL-8 (a), IL-10 (b) and GM-CSF (c). Sampling times: A: preoperative, B: postoperative at day of surgery, C: postoperative Day 1. GM-CSF, granulocyte macrophage-colony stimulating factor; IL, interleukin; TLR2 SNP, tolllike receptor 2 single-nucleotide polymorphism carrier; TLR4 SNP, toll-like receptor 4 single-nucleotide polymorphism carrier. Number of patients in each group: non-carrier $=274$, TLR4 SNP $=51$, TLR2 SNP $=13$. Values are shown as mean and $95 \%$ confidence intervals. ${ }^{*} P<0.05$ compared to $A ;+P<0.05$ compared to $B ; \neq P<0.05$ compared to non-carrier.

rose significantly from $A$ to $B$ in all three groups and from $\mathrm{A}$ to $\mathrm{C}$ in non-carrier and TLR4 SNP carrier patients. In the non-carrier group GM-CSF levels dropped significantly from B to C. GM-CSF levels at sample time B were significantly lower in the TLR4 SNP group compared to non-carriers (Figure 2c).

\section{Discussion}

Systemic inflammation, as a result of major surgery or sepsis, has a distinct effect on the immune-adrenal crosstalk. We report for the first time of an association between the presence of a SNP (here: TLR4) and perioperative ACTH levels. Changes of ACTH levels were 
Table 2 TLR4/TLR2 polymorphisms and time course of perioperative cytomine serum concentrations

\begin{tabular}{|c|c|c|c|c|}
\hline & & \multicolumn{3}{|c|}{ Sample times } \\
\hline & & $A$ & B & $\mathrm{C}$ \\
\hline \multirow[t]{3}{*}{ IL-1 $\boldsymbol{\beta}(\mathrm{pg} / \mathrm{ml})$} & non-carrier & $8.2(3.5$ to 12.8$)$ & 14.4 (9.3 to 19.4$)$ & $9.9(4.8$ to 15.0$)$ \\
\hline & TLR4 SNP & $6.7(-4.1$ to 17.5$)$ & $12.3(1.2$ to 23.5$)$ & 11.5 (0.3 to 22.7$)$ \\
\hline & TLR2 SNP & $1.2(-20.2$ to 22.6$)$ & 29.3 (6.0 to 52.6$)$ & $12.4(-12.0$ to 36.9$)$ \\
\hline \multirow[t]{3}{*}{ IL-2 (pg/ml) } & non-carrier & 2.6 (1.3 to 3.9$)$ & 3.0 (1.7 to 4.4$)$ & 2.4 (1.0 to 3.8$)$ \\
\hline & TLR4 SNP & $2.0(-1.0$ to 5.0$)$ & $2.8(-0.2$ to 5.9$)$ & $3.3(0.2$ to 6.4$)$ \\
\hline & TLR2 SNP & $1.1(-4.8$ to 7.0$)$ & $1.8(-4.6$ to 8.2$)$ & $1.0(-5.7$ to 7.8$)$ \\
\hline \multirow[t]{3}{*}{ IL-4 (pg/ml) } & non-carrier & $4.9(2.7$ to 7.1$)$ & 4.6 (2.2 to 7.0$)$ & 4.2 (1.8 to 6.6$)$ \\
\hline & TLR4 SNP & $1.7(-3.5$ to 6.8$)$ & $2.0(-3.3$ to 7.3$)$ & $1.8(-3.6$ to 7.2$)$ \\
\hline & TLR2 SNP & $4.5(-5.7$ to 14.7$)$ & $2.4(-8.7$ to 13.5$)$ & $3.1(-8.6$ to 14.7$)$ \\
\hline \multirow[t]{3}{*}{ IL-5 (pg/ml) } & non-carrier & 1.5 (0.7 to 2.4$)$ & 2.6 (1.7 to 3.6$)$ & 1.5 (0.6 to 2.5$)$ \\
\hline & TLR4 SNP & $0.9(-1.1$ to 2.9$)$ & $1.4(-0.7$ to 3.5$)$ & $0.7(-1.4$ to 2.9$)$ \\
\hline & TLR2 SNP & $1.1(-3.0$ to 5.1$)$ & $1.4(-3.0$ to 5.8$)$ & $0.8(-3.8$ to 5.36$)$ \\
\hline \multirow[t]{3}{*}{ IL-6 (pg/ml) } & non-carrier & $18.8(-48.4$ to 86.0$)$ & $554.1(481.7 \text { to } 626.4)^{a}$ & $350.4(277.1 \text { to } 423.7)^{a b}$ \\
\hline & TLRA SNP & $24.0(-131.6$ to 179.7$)$ & $422.5(262.1 \text { to } 583.0)^{a}$ & $344.7(182.6 \text { to } 506.9)^{a}$ \\
\hline & TLR2 SNP & $14.3(-294.0$ to 322.7$)$ & $696.3(361.1 \text { to } 1031.5)^{a}$ & 405.7 (54.1 to 757.2 ) \\
\hline \multirow[t]{3}{*}{ TNF- $\alpha(p g / m l)$} & non-carrier & $4.9(-7.6$ to 17.4$)$ & $12.9(-0.6$ to 26.3$)$ & $8.7(-4.9$ to 22.3$)$ \\
\hline & TLR4 SNP & $0.3(-28.5$ to 29.2$)$ & $1.9(-27.8$ to 31.7$)$ & $1.0(-29.1$ to 31.1$)$ \\
\hline & TLR2 SNP & $0.3(-56.9$ to 57.5$)$ & $3.4(-58.8$ to 65.5$)$ & 1.5 (-63.7 to 66.7$)$ \\
\hline
\end{tabular}

Sampling times: A: preoperative, B: postoperative at day of surgery, C: postoperative Day 1 . IL, interleukin; TLR2 SNP, toll-like receptor2 single-nucleotide polymorphism carrier; TLR4 SNP, toll-like receptor4 single-nucleotide polymorphism carrier; TNF, tumor necrosis factor. ${ }^{a} P<0.05$ compared to $A ;{ }^{b} P<0.05$ compared to B. Data are given as mean and $95 \%$ confidence intervals.

significantly lower in the TLR4 SNP carrier group compared to non-carriers. Both, TLR4 SNP carriers and non-carriers showed a significant rise of cortisol serum levels following cardiac surgery. This rise was preceded/ accompanied by a significant ACTH rise only in noncarriers. Furthermore, our results link for the first time a SNP (here: TLR4) with differences in perioperative time courses of IL-8, IL-10 and GM-CSF serum levels, that is, in contrast to non-carriers, TLR4 SNP carriers demonstrated significantly lower immediate postoperative serum concentrations.

Major surgery, for example, cardiac surgery with $\mathrm{CPB}$, leads to a systemic inflammation which is accompanied by an activation of the HPA axis [28,29]. A significant rise of postoperative serum cortisol in cardiac surgery patients has been described in several studies over the last decades [30-34]. The rise of endocrine stress markers seems not to depend on the individual, anticipatory stress of the patient awaiting surgery, the type of postoperative respiratory weaning, perioperative beta blockade or sufentanil or fentanyl doses [35-39].

Dissociation between cortisol and ACTH levels following major surgery has been observed, particularly on the first postoperative day, whereas ACTH levels spread strongly immediately after surgery $[23,37,40,41]$. ACTH is produced primarily by the anterior pituitary gland. Alternative sources described in the literature are immunocompetent cells, adrenal gland and inflammatory sites [42-45]. Furthermore, there are hints, that the splanchnic nerve is involved in adrenal cortex regulation $[46,47]$. As we observed a similar release of cortisol in TLR4 SNP carriers and non-carriers, the above mentioned alternative adrenal cortex stimuli can be discussed as compensatory mechanisms for cortisol release in TLR4 SNP carriers. Therefore, one could speculate that in TLR4 SNP carriers, cortisol release might be rather locally triggered, while adrenal glands of noncarriers are mainly controlled by systemic ACTH. In an ACTH stimulation study in 45 cardiac surgery patients, $11(25 \%)$ had an impaired cortisol response [48]. These effects could be explained by our findings in that TLR4 SNP carriers were part of the patient population.

Pro-inflammatory cytokines are involved in the release of corticotropin releasing hormone $(\mathrm{CRH})$ and subsequent $\mathrm{ACTH}$ release [49]. In CRH-knockout mice viral infection leads to an $\mathrm{ACTH}$ independent corticosterone response, which is associated with significantly higher IL-6 plasma concentrations compared to WT mice [50]. This could be interpreted as exaggerated IL- 6 levels compensating for the lack of ACTH. However, in our study changes in IL-6 levels did not differ between the groups. Also, GM-CSF is able to trigger cortisol release [51]; however, we found changes in GM-CSF concentration to be significantly lower in the TLR4 SNP carrier group. None of the measured cytokines were found to be higher up-regulated in the TLR4 SNP group compared to the non-carrier cohort. Therefore, our data do not support the concept of cytokines being 
compensatory up-regulated counterbalancing low ACTH levels to allow sufficient cortisol levels.

Also, in critically ill patients dissociations between ACTH and cortisol have been described, particularly from days 4 to 5 post trauma or beginning of sepsis [52]. A clinical study (Corticus) including patients with severe sepsis or septic shock demonstrated that survivors had lower baseline cortisol levels and significant higher $\Delta \max$ (that is, peak cortisol following ACTH stimulation minus baseline cortisol) compared to nonsurvivors [53]. In critically ill, for example, septic patients, adrenal insufficiency can occur and it has been postulated that particularly these patients could benefit from a therapy with glucosteroids $[54,55]$. However, the diagnosis of adrenal insufficiency in critically ill is difficult and there is still an ongoing search for an adequate diagnostic tool. The diagnosis of adrenal insufficiency in septic patients examined in multicenter trials is complicated by a high inter-assay variation [56]. In a recently published recommendation upon the diagnosis and management of corticosteroid insufficiency in critically ill adult patients, the standard ACTH stimulation test for diagnosing adrenal insufficiency is not recommended to be performed as a routine [57]. In literature, the prevalence of adrenal insufficiency in critically ill patients varies widely between the studies ( 0 to $77 \%$ ) [52,57,58]. The question arising from our results is: How do adrenal glands from TLR4 SNP carriers respond to an ACTH stimulation test as they are obviously releasing cortisol less dependent/independent from ACTH during systemic inflammation? Does ACTH stimulation result in even higher cortisol serum levels or are adrenal glands of TLR4 SNP carriers insensitive to ACTH? This should be taken into consideration when interpreting completed, and planning for new clinical trials on HPA axis regulation in septic patients. Particularly, considering the fact that TLR4 SNP carriers demonstrate a higher risk for developing sepsis, that is, the frequency of TLR4 SNP carriers in a septic patient cohort is higher (approximately 20\%) compared to the normal population or, for example, cardiac surgical patients [59-61].

A perioperative rise of several cytokines following major/cardiac surgery is well described $[19,28,29,62]$. Regarding perioperative TNF- $\alpha$ and IL- 6 plasma concentrations and the influence of TLR4 SNP (Asp299Gly/ Thr399Ile), our findings are similar to previous trials. In abdominal surgical patients neither non-carriers nor TLR4 SNP carriers showed a significant rise in TNF- $\alpha$ postoperatively. However, both cohorts demonstrated a significant IL- 6 rise compared to preoperative baseline concentrations. Neither TNF- $\alpha$, nor IL- 6 plasma concentrations differed significantly between non-carriers and TLR4 SNP carriers [63]. Furthermore, there was no difference of IL-6 levels in a healthy population (8 TLR4
SNP vs 49 non-carriers) treated with low dose LPS [64]. A diminished Human Leukocyte Antigen (HLA-DR) expression on monocytes and B-lymphocytes following cardiac surgery can in vitro be reversed by GM-CSF [65]. One could therefore speculate, that TLR4 SNP carriers would express less HLA-DR, possibly making them more susceptible to postoperative infections. On the other hand IL-10 can reverse HLA-DR up-regulation [66]. Translated to our results this would mean better immune competence of TLR4 SNP carriers. Post surgery and/or trauma IL- 8 and IL-10 plasma levels are significantly higher in nonsurvivors compared to survivors [67], which would translated to our study result in a higher mortality in the non-carrier group. However, our study did not find differences in 28-day outcome between the cohorts, which might be due to an underpowered sample size.

Ex vivo stimulation of whole blood or isolated monocytes revealed similar cytokine responses as observed in our study: The presence of TLR4 SNP did not influence the LPS induced release of TNF- $\alpha$, IL- $1 \beta$ or IL- 6 compared to non-carriers. However, comparable to our results, TLR4 SNP led to a reduced IL-10 release $[68,69]$. With IL-10 enhancing ACTH release [70], the significant lower rise of IL-10 in TLR4 SNP carriers could have accounted for the absence of a significant change in ACTH levels in this genotype.

During cardiac surgery, phases of hypoperfusion with consecutive tissue hypoxia occur. Hypoxia induces expression and increases signaling of TLRs [71]. This seems to be particularly true for TLR2 and TLR6 [72]. You could therefore speculate that hypoxia induced TLR2 expression is negatively influenced by the presence of TLR2 SNP. The TLR2 SNP carrier group in this study is probably too small to estimate whether the SNP for TLR2 would have an effect on, for example, cytokine release. Serum concentrations of cytokines investigated in this study do not differ between non-carriers and TLR2 SNP carriers.

A study in patients $(n=94)$ being admitted to the intensive care unit for various reasons (sepsis, cardiovascular failure, pancreatitis, respiratory failures, and so on) failed to demonstrate a correlation between SNP TLR4 Asp299Gly and length of stay (hospital or intensive care). However, mortality was higher in TLR4 SNP carriers [61]. Our study did not find a correlation between hospital or intensive care length of stay (data not shown) or mortality (see results) and TLR2 or TLR4 SNP. As a further limitation of this study, the TLR2 SNP carrier group compared to the non-carrier group is too small to draw major conclusions. Also, the study is underpowered for detecting significant differences in morbidity or mortality between the cohorts. Further studies are needed to determine if the observations made in this study have any impact on clinical outcome. 
With this study we translated observations made in animals to a clinical scenario. In TLR2 and TLR4 knockout mice we demonstrated the altered regulation of HPA axis and cytokines during systemic inflammation. In patients, polymorphisms of TLR2 and TLR4 influence HPA axis and cytokine response to surgical stress, that is, systemic inflammation.

\section{Conclusions}

In conclusion, this clinical study in cardiac surgical patients demonstrates a diminished perioperative ACTH release in TLR4 SNP carrying patients. Carriers and non-carriers, however, demonstrated the same transient, perioperative rise in cortisol serum concentrations, indicating that in TLR4 polymorphism carriers, cortisol release seems to be less dependent or even independent of systemic ACTH concentrations. These findings should be considered when diagnosing and treating adrenal insufficiency in patients with systemic inflammation, for example, sepsis. Furthermore, TLR4 SNP carriers demonstrated a significantly reduced release of the cytokines IL-8, IL-10 and GM-CSF compared to noncarriers. TNF- $\alpha$, IL-1 $\beta$, IL-2, IL-4, IL- 5 and IL-6 did not differ between TLR4 SNP carriers and non-carriers.

\section{Key messages}

- Cardiac surgical patients carrying a genetic variation of TLR4 demonstrate diminished perioperative ACTH release.

- However, postoperative cortisol rise did not differ from non-carriers, indicating ACTH not to be the primary stimulus for perioperative cortisol release in TLR4 carriers.

- This finding might have impact on interpreting previous and planning new studies investigating adrenal insufficiency in patients with systemic inflammation (for example, sepsis).

- TLR4 polymorphism carriers demonstrated lower postoperative peaks of the cytokines IL-8, IL-10 and GM-CSF.

\footnotetext{
Abbreviations

ACT: activated clotting time; ACTH: adrenocorticotropic hormone; CABG: coronary artery bypass graft; CPB: cardiopulmonary bypass; $\mathrm{CRH}$ : corticotropin releasing hormone; CRP: C-reactive protein; DNA: deoxyribonucleic acid; GM-CSF: granulocyte macrophage-colony stimulating factor; HLA-DR: Human Leukocyte Antigen; HPA: hypothalamic-pituitaryadrenal; ICU: intensive care unit; IFN: interferon; IL: interleukin; LPS: lipopolysaccharide; LTA: lipoteichoic acid; MAP: mean arterial blood pressure; SNP: single nucleotide polymorphisms; TLR: Toll-like receptor; TNF: tumor necrosis factor; VS: valve surgery.
}

\section{Acknowledgements}

The authors thank Saskia Hoppe, Soo-Ji Park, Irini Solomonidou, Stefanie Vennekötter and Michaela Monte for their contribution to the study. K.Z. was supported by grants of the Deutsche Forschungsgemeinschaft (DFG) (Za243/ 8-1, 8-2 and 9-1). A.K. was supported by a grant of the
Forschungskommission, University Düsseldorf, Germany. Some preliminary data of this study were presented at the 8th World Congress on Trauma, Shock, Inflammation and Sepsis - TSIS 2010 in Munich, Germany. Abstract: Inflamm. Res. (2010) 59 (Suppl 1):S103 [73]

\section{Author details}

${ }^{1}$ Clinic of Anaesthesiology, Intensive Care Medicine and Pain Therapy, J.W.Goethe-University Hospital, Theodor-Stern-Kai 7, Frankfurt am Main 60590, Germany. ${ }^{2}$ Institute for Microbiology and Hygiene, Charite-University Medical Center Berlin, Dorotheenstrasse 96, Berlin 10117, Germany. ${ }^{3}$ Department of Endocrinology, Diabetes, and Rheumatology, University Hospital Duesseldorf, Moorenstrasse 5, Duesseldorf 40225, Germany. ${ }^{4}$ Department of

Anesthesiology and Intensive Care, University Hospital Bonn, Sigmund-FreudStrasse 25, Bonn 53105, Germany. ${ }^{5}$ Service de Chirurgie Vasculaire, Centre Hospitalier du Kirchberg, 9, rue Edward Steichen, Luxembourg 2540, Luxembourg. ${ }^{6}$ Department of Thoracic and Cardiovascular Surgery, University Hospital Duesseldorf, Moorenstrasse 5, Duesseldorf 40225, Germany.

${ }^{7}$ SCOSSiS Statistical consulting, Zeltinger Strasse 58 G, Berlin 13465, Germany. ${ }^{8}$ Department of Medicine III, University Hospital Carl Gustav Carus,

Technische Universität Dresden, Fetscherstrasse 74, Dresden 01307, Germany.

\section{Authors' contributions}

AK contributed to idea and design of the study, was responsible for acquisition of patient data, collected and analyzed the data and wrote the manuscript. LH and RRS performed SNP analyzes and contributed to the drafts of the manuscript. MS performed ACTH and cortisol analyzes and contributed to the drafts of the manuscript. $O B$ and contributed to the writing of the paper, collected data and assisted in patient recruitment. DG and MK collected data and assisted in patient recruitment. SRB helped to design the study and participated in the interpretation of all data. CS performed statistical analyzes. KZ conceived of the study, obtained funding, participated in its design and coordination, headed the project and helped to draft the manuscript. All authors read and approved the final manuscript.

\section{Competing interests}

The authors declare that they have no competing interests.

Received: 31 January 2011 Revised: 16 March 2011

Accepted: 5 April 2011 Published: 5 April 2011

\section{References}

1. Trinchieri $\mathrm{G}$, Sher $\mathrm{A}$ : Cooperation of Toll-like receptor signals in innate immune defence. Nat Rev Immunol 2007, 7:179-190.

2. Bornstein SR, Ziegler CG, Krug AW, Kanczkowski W, Rettori V, McCann SM, Wirth M, Zacharowski K: The role of toll-like receptors in the immuneadrenal crosstalk. Ann N Y Acad Sci 2006, 1088:307-318.

3. van den Boogaard M, Ramakers BP, van Alfen N, van der Werf SP, Fick WF Hoedemaekers CW, Verbeek MM, Schoonhoven L, van der Hoeven JG, Pickkers P: Endotoxemia-induced inflammation and the effect on the human brain. Crit Care 2010, 14:R81.

4. Pittet $Y K$, Berger MM, Pluess $\Pi$, Voirol P, Revelly JP, Tappy L, Chiolero RL: Blunting the response to endotoxin in healthy subjects: effects of various doses of intravenous fish oil. Intensive Care Med 2010, 36:289-295.

5. Clodi M, Vila G, Geyeregger R, Riedl M, Stulnig TM, Struck J, Luger TA, Luger A: Oxytocin alleviates the neuroendocrine and cytokine response to bacterial endotoxin in healthy men. Am J Physiol Endocrinol Metab 2008, 295:E686-E691.

6. Bornstein SR, Zacharowski P, Schumann RR, Barthel A, Tran N, Papewalis C, Rettori V, McCann SM, Schulze-Osthoff K, Scherbaum WA, Tarnow J, Zacharowski K: Impaired adrenal stress response in Toll-like receptor 2deficient mice. Proc Natl Acad Sci USA 2004, 101:16695-16700.

7. Zacharowski K, Zacharowski PA, Koch A, Baban A, Tran N, Berkels R, Papewalis C, Schulze-Osthoff K, Knuefermann P, Zähringer U, Schumann RR, Rettori V, McCann SM, Bornstein SR: Toll-like receptor 4 plays a crucial role in the immune-adrenal response to systemic inflammatory response syndrome. Proc Natl Acad Sci USA 2006, 103:6392-6397.

8. Lorenz E, Mira JP, Cornish KL, Arbour NC, Schwartz DA: A novel polymorphism in the toll-like receptor 2 gene and its potential association with staphylococcal infection. Infect Immun 2000, 68:6398-6401. 
9. Schroder NW, Hermann C, Hamann L, Gobel UB, Hartung T, Schumann RR: High frequency of polymorphism Arg753GIn of the Toll-like receptor-2 gene detected by a novel allele-specific PCR. J Mol Med 2003, 81:368-372.

10. Woehrle T, Du W, Goetz A, Hsu HY, Joos TO, Weiss M, Bauer U, Brueckner UB, Marion SE: Pathogen specific cytokine release reveals an effect of TLR2 Arg753Gln during Candida sepsis in humans. Cytokine 2008, 41:322-329.

11. Emingil G, Berdeli A, Baylas H, Saygan BH, Gurkan A, Kose T, Atilla G: Tolllike receptor 2 and 4 gene polymorphisms in generalized aggressive periodontitis. J Periodontol 2007, 78:1968-1977.

12. Berdeli A, Emingil G, Han SB, Gurkan A, Atilla G, Kose T, Baylas H: TLR2 Arg753Gly, TLR4 Asp299Gly and Thr399lle gene polymorphisms are not associated with chronic periodontitis in a Turkish population. J Clin Periodontol 2007, 34:551-557.

13. Kutukculer N, Yeniay BS, Aksu G, Berdeli A: Arg753Gln polymorphism of the human toll-like receptor-2 gene in children with recurrent febrile infections. Biochem Genet 2007, 45:507-514.

14. Hamann L, Gomma A, Schroder NW, Stamme C, Glaeser C, Schulz S, Gross M, Anker SD, Fox K, Schumann RR: A frequent toll-like receptor (TLR)-2 polymorphism is a risk factor for coronary restenosis. J Mol Med 2005, 83:478-485.

15. Ferwerda B, McCall MB, Alonso S, Giamarellos-Bourboulis EJ, Mouktaroudi $M$, Izagirre N, Syafruddin D, Kibiki G, Cristea T, Hijmans A, Hamann L, Israel S, ElGhazali G, Troye-Blomberg M, Kumpf O, Maiga B, Dolo A, Doumbo O, Hermsen CC, Stalenhoef AF, van Crevel R, Brunner HG, Oh DY, Schumann RR, de la Rúa C, Sauerwein R, Kullberg BJ, van der Ven AJ, van der Meer JW, Netea MG: TLR4 polymorphisms, infectious diseases, and evolutionary pressure during migration of modern humans. Proc Natl Acad Sci USA 2007, 104:16645-16650.

16. Arbour NC, Lorenz E, Schutte BC, Zabner J, Kline JN, Jones M, Frees K, Watt JL, Schwartz DA: TLR4 mutations are associated with endotoxin hyporesponsiveness in humans. Nat Genet 2000, 25:187-191.

17. Schwartz DA: Inhaled endotoxin, a risk for airway disease in some people. Respir Physiol 2001, 128:47-55.

18. Marsik C, Jilma B, Joukhadar C, Mannhalter C, Wagner O, Endler G: The Tolllike receptor 4 Asp299Gly and Thr399lle polymorphisms influence the late inflammatory response in human endotoxemia. Clin Chem 2005, 51:2178-2180.

19. Levy JH, Tanaka KA: Inflammatory response to cardiopulmonary bypass. Ann Thorac Surg 2003, 75:S715-S720.

20. Rinder C: Cellular inflammatory response and clinical outcome in cardiac surgery. Curr Opin Anaesthesiol 2006, 19:65-68.

21. Velissaris T, Tang AT, Murray M, Mehta RL, Wood PJ, Hett DA, Ohri SK: A prospective randomized study to evaluate stress response during beating-heart and conventional coronary revascularization. Ann Thorac Surg 2004, 78:506-512.

22. Roth-lsigkeit $A$, Dibbelt $L$, Schmucker $P$, Seyfarth M: The immune-endocrine interaction varies with the duration of the inflammatory process in cardiac surgery patients. J Neuroendocrinol 2000, 12:546-552.

23. Roth-lsigkeit AK, Schmucker P: Postoperative dissociation of blood levels of cortisol and adrenocorticotropin after coronary artery bypass grafting surgery. Steroids 1997, 62:695-699.

24. Mitchell JD, Grocott HP, Phillips-Bute B, Mathew JP, Newman MF, BarYosef S: Cytokine secretion after cardiac surgery and its relationship to postoperative fever. Cytokine 2007, 38:37-42.

25. Hamann L, Hamprecht A, Gomma A, Schumann RR: Rapid and inexpensive real-time PCR for genotyping functional polymorphisms within the Tolllike receptor -2, -4, and -9 genes. J Immunol Methods 2004, 285:281-291.

26. Paramonova I, Haase M, Mülders-Opgenoorth B, Ansurudeen-Rafi I, Bornstein SR, Papewalis C, Schinner S, Schott M, Scherbaum WA, Willenberg HS: The effects of the endothelium on adrenal steroidogenesis and growth are mainly mediated by proteins other than endothelin-1. Horm Metab Res 2010, 42:840-845.

27. Koch A, Zacharowski K, Boehm O, Stevens M, Lipfert P, von Giesen HJ Wolf A, Freynhagen R: Nitric oxide and pro-inflammatory cytokines correlate with pain intensity in chronic pain patients. Inflamm Res 2007, 56:32-37.

28. Butler J, Rocker GM, Westaby S: Inflammatory response to cardiopulmonary bypass. Ann Thorac Surg 1993, 55:552-559.

29. Koch A, Zacharowski P, Boehm O, Zacharowski K: Innate immunity, coagulation and surgery. Front Biosci 2009, 14:2970-2982.
30. Taylor KM, Jones JV, Walker MS, Rao S, Bain WH: The cortisol response during heart-lung bypass. Circulation 1976, 54:20-25.

31. Walker WF: Adrenal response to cardiac surgery. Proc R Soc Med 1965, 58:1015-1017.

32. Rasmussen BS, Sollid J, Knudsen L, Christensen T, Toft E, Tonnesen E: The release of systemic inflammatory mediators is independent of cardiopulmonary bypass temperature. J Cardiothorac Vasc Anesth 2007, 21:191-196.

33. Roth-Isigkeit A, Dibbelt L, Eichler W, Schumacher J, Schmucker P: Blood levels of atrial natriuretic peptide, endothelin, cortisol and ACTH in patients undergoing coronary artery bypass grafting surgery with cardiopulmonary bypass. J Endocrinol Invest 2001, 24:777-785.

34. Vogeser M, Groetzner J, Kupper C, Briegel J: The serum cortisol:cortisone ratio in the postoperative acute-phase response. Horm Res 2003, 59:293-296.

35. Roth-Isigkeit A, Ocklitz E, Bruckner S, Ros A, Dibbelt L, Friedrich HJ, Gehring H, Schmucker P: Development and evaluation of a video program for presentation prior to elective cardiac surgery. Acta Anaesthesiol Scand 2002, 46:415-423.

36. Calzia E, Koch M, Stahl W, Radermacher P, Brinkmann A: Stress response during weaning after cardiac surgery. Br J Anaesth 2001, 87:490-493.

37. Zaugg M, Tagliente T, Lucchinetti E, Jacobs E, Krol M, Bodian C, Reich DL, Silverstein JH: Beneficial effects from beta-adrenergic blockade in elderly patients undergoing noncardiac surgery. Anesthesiology 1999, 91:1674-1686.

38. Lacoumenta S, Yeo TH, Paterson JL, Burrin JM, Hall GM: Hormonal and metabolic responses to cardiac surgery with sufentanil-oxygen anaesthesia. Acta Anaesthesiol Scand 1987, 31:258-263.

39. von Bormann B, Sturm G, Kling D, Scheld HH, Boldt J, Hempelmann G: [Significance of endocrine parameters of stress]. Anaesthesist 1985 34:280-286.

40. Bornstein SR, Engeland WC, Ehrhart-Bornstein M, Herman JP: Dissociation of ACTH and glucocorticoids. Trends Endocrinol Metab 2008, 19:175-180.

41. Dimopoulou I, Tzanela M, Vassiliadi D, Mavrou I, Kopterides P, Orfanos S, Kotanidou A, Kontogiannopoulou S, Vasdekis S, Tsangaris I, Armaganidis A, Macheras A, llias I, Kostopanagiotou G, Tsagarakis S: Pituitary-adrenal responses following major abdominal surgery. Hormones (Athens) 2008, 7:237-242

42. Meyer WJ III, Smith EM, Richards GE, Cavallo A, Morrill AC, Blalock JE: In vivo immunoreactive adrenocorticotropin (ACTH) production by human mononuclear leukocytes from normal and ACTH-deficient individuals. $J$ Clin Endocrinol Metab 1987, 64:98-105.

43. Jones $C T$, Edwards AV: Release of adrenocorticotrophin from the adrenal gland in the conscious calf. J Physiol 1990, 426:397-407.

44. Crofford LJ, Sano H, Karalis K, Webster EL, Goldmuntz EA, Chrousos GP. Wilder RL: Local secretion of corticotropin-releasing hormone in the joints of Lewis rats with inflammatory arthritis. J Clin Invest 1992. 90:2555-2564

45. Ekman R, Servenius B, Castro MG, Lowry PJ, Cederlund AS, Bergman O, Sjogren $\mathrm{HO}$ : Biosynthesis of corticotropin-releasing hormone in human T-lymphocytes. J Neuroimmunol 1993, 44:7-13.

46. Engeland WC: Functional innervation of the adrenal cortex by the splanchnic nerve. Horm Metab Res 1998, 30:311-314.

47. Bornstein SR, Ehrhart-Bornstein M, Scherbaum WA, Pfeiffer EF, Holst J]: Effects of splanchnic nerve stimulation on the adrenal cortex may be mediated by chromaffin cells in a paracrine manner. Endocrinology 1990, 127:900-906

48. Henzen C, Kobza R, Schwaller-Protzmann B, Stulz P, Briner VA: Adrenal function during coronary artery bypass grafting. Eur J Endocrinol 2003 148:663-668.

49. Navarra $P$, Tsagarakis $S$, Faria MS, Rees LH, Besser GM, Grossman AB: Interleukins-1 and -6 stimulate the release of corticotropin-releasing hormone-41 from rat hypothalamus in vitro via the eicosanoid cyclooxygenase pathway. Endocrinology 1991, 128:37-44.

50. Silverman MN, Miller AH, Biron CA, Pearce BD: Characterization of an interleukin-6- and adrenocorticotropin-dependent, immune-to-adrenal pathway during viral infection. Endocrinology 2004, 145:3580-3589.

51. Crispino S, Lissoni P, Ardizzoia A, Barni S, Rovelli F, Tancini G: Effects of granulocyte-macrophage colony stimulating factor on cortisol, growth hormone, prolactin and melatonin in cancer patients (short communication). J Biol Regul Homeost Agents 1992, 6:142-144. 
52. Vermes I, Beishuizen A: The hypothalamic-pituitary-adrenal response to critical illness. Best Pract Res Clin Endocrinol Metab 2001, 15:495-511.

53. Lipiner-Friedman D, Sprung CL, Laterre PF, Weiss Y, Goodman SV Vogeser M, Briegel J, Keh D, Singer M, Moreno R, Bellissant E, Annane D, Corticus Study Group: Adrenal function in sepsis: the retrospective Corticus cohort study. Crit Care Med 2007, 35:1012-1018.

54. Cooper MS, Stewart PM: Corticosteroid insufficiency in acutely ill patients. N Engl J Med 2003, 348:727-734

55. Bornstein SR: Predisposing factors for adrenal insufficiency. N Engl J Med 2009, 360:2328-2339.

56. Briegel J, Sprung CL, Annane D, Singer M, Keh D, Moreno R, Möhnle P, Weiss Y, Avidan A, Brunkhorst FM, Fiedler F, Vogeser M, CORTICUS Study Group: Multicenter comparison of cortisol as measured by different methods in samples of patients with septic shock. Intensive Care Med 2009, 35:2151-2156.

57. Marik PE, Pastores SM, Annane D, Meduri GU, Sprung CL, Arlt W, Keh D, Briegel J, Beishuizen A, Dimopoulou I, Tsagarakis S, Singer M, Chrousos GP, Zaloga G, Bokhari F, Vogeser M, American College of Critical Care Medicine: Recommendations for the diagnosis and management of corticosteroid insufficiency in critically ill adult patients: consensus statements from an international task force by the American College of Critical Care Medicine. Crit Care Med 2008, 36:1937-1949.

58. Kenyon N: Defining adrenal insufficiency in septic shock. Crit Care Med 2003, 31:321-323.

59. Agnese DM, Calvano JE, Hahm SJ, Coyle SM, Corbett SA, Calvano SE, Lowry SF: Human toll-like receptor 4 mutations but not CD14 polymorphisms are associated with an increased risk of gram-negative infections. J Infect Dis 2002, 186:1522-1525.

60. Lorenz E, Mira JP, Frees KL, Schwartz DA: Relevance of mutations in the TLR4 receptor in patients with gram-negative septic shock. Arch Intern Med 2002, 162:1028-1032

61. Child NJ, Yang IA, Pulletz MC, Courcy-Golder K, Andrews AL, Pappachan VJ, Holloway JW: Polymorphisms in Toll-like receptor 4 and the systemic inflammatory response syndrome. Biochem Soc Trans 2003, 31:652-653.

62. Bown MJ, Nicholson ML, Bell PR, Sayers RD: Cytokines and inflammatory pathways in the pathogenesis of multiple organ failure following abdominal aortic aneurysm repair. Eur J Vasc Endovasc Surg 2001, 22:485-495.

63. Kumpf O, Hamann L, Schlag PM, Schumann RR: Pre- and postoperative cytokine release after in vitro whole blood lipopolysaccharide stimulation and frequent toll-like receptor 4 polymorphisms. Shock 2006, 25:123-128.

64. Calvano JE, Bowers DJ, Coyle SM, Macor M, Reddell MT, Kumar A Calvano SE, Lowry SF: Response to systemic endotoxemia among humans bearing polymorphisms of the Toll-like receptor 4 (hTLR4). Clin Immunol 2006, 121:186-190.

65. Borgermann J, Friedrich I, Scheubel R, Kuss O, Lendemans S, Silber RE, Kreuzfelder E, Flohe S: Granulocyte-macrophage colony-stimulating factor (GM-CSF) restores decreased monocyte HLA-DR expression after cardiopulmonary bypass. Thorac Cardiovasc Surg 2007, 55:24-31.

66. Kim OY, Monsel A, Bertrand M, Coriat P, Cavaillon JM, Adib-Conquy M: Differential down-regulation of HLA-DR on monocyte subpopulations during systemic inflammation. Crit Care 2010, 14:R61.

67. Hranjec T, Swenson BR, Dossett LA, Metzger R, Flohr TR, Popovsky KA, Bonatti HJ, May AK, Sawyer RG: Diagnosis-dependent relationships between cytokine levels and survival in patients admitted for surgical critical care. J Am Coll Surg 2010, 210:833-836.

68. Dehus O, Bunk S, von Aulock S, Hermann C: IL-10 release requires stronger toll-like receptor 4-triggering than TNF: a possible explanation for the selective effects of heterozygous TLR4 polymorphism Asp(299) Gly on IL-10 release. Immunobiology 2008, 213:621-627.

69. von Aulock S, Schröder NW, Gueinzius K, Traub S, Hoffmann S, Graf K, Dimmeler S, Hartung T, Schumann RR, Hermann C: Heterozygous toll-like receptor 4 polymorphism does not influence lipopolysaccharide-induced cytokine release in human whole blood. J Infect Dis 2003, 188:938-943.

70. Smith EM, Cadet P, Stefano GB, Opp MR, Hughes TK Jr: IL-10 as a mediator in the HPA axis and brain. J Neuroimmunol 1999, 100:140-148.

71. Eltzschig HK, Carmeliet P: Hypoxia and inflammation. N Engl J Med 2011, 364:656-665
72. Kuhlicke J, Frick JS, Morote-Garcia JC, Rosenberger P, Eltzschig HK: Hypoxia inducible factor (HIF)-1 coordinates induction of Toll-like receptors TLR2 and TLR6 during hypoxia. PLoS One 2007, 2:e1364.

73. Koch A, Hamann L, Schumann R, Schwenke C, Bornstein S, Zacharowski K: Single nucleotide polymorphism (SNP) of Toll-like receptor (TLR) 4 influences hypothalamic-pituitary-adrenal (HPA) axis regulation in patients with postoperative systemic inflammation. Inflamm Res 2010, 59 Suppl 1:S103.

doi:10.1186/cc10130

Cite this article as: Koch et al:: Genetic variation of TLR4 influences immunoendocrine stress response: an observational study in cardiac surgical patients. Critical Care 2011 15:R109.

\section{Submit your next manuscript to BioMed Central and take full advantage of:}

- Convenient online submission

- Thorough peer review

- No space constraints or color figure charges

- Immediate publication on acceptance

- Inclusion in PubMed, CAS, Scopus and Google Scholar

- Research which is freely available for redistribution

Submit your manuscript at www.biomedcentral.com/submit
C Biomed Central 